\title{
Cardiac Strain as a Predictor of Adverse Events and Ventricular Remodeling: A Cohort Study
}

\section{yanjun GONG ( $\nabla$ gongyanjun111@163.com )}

Peking University First Hospital https://orcid.org/0000-0003-1281-1073

\section{Yuan Lu}

affiliated hospital of suzhou medical university

Jessica C. Huo

zionsville community high school

\section{Zhi Wang}

Peking University First Hospital

\section{Fan Yang}

Peking University First Hospital

\section{Shu Fang}

Peking University First Hospital

\section{Lin Qiu}

Peking University First Hospital

Jianxing Qiu

Peking University First Hospital

\section{Yong Huo}

Peking University First Hospital

\section{Research article}

Keywords: cardiac magnetic resonance imaging, cardiac strain, myocardial infarction, LV remodeling

Posted Date: September 8th, 2020

DOl: https://doi.org/10.21203/rs.3.rs-41701/v2

License: (a) (i) This work is licensed under a Creative Commons Attribution 4.0 International License. Read Full License 


\section{Abstract}

Background: It remains controversial whether cardiac strain accurately predicts adverse events after acute ST-segment elevation myocardial infarction (STEMI). The aim of the present study was to evaluate the effects of cardiac strain revealed on cardiac magnetic resonance (CMR) imaging on cardiac events and adverse left ventricular (LV) remodeling.

Methods: Between February 2015 and September 2016, we conducted a prospective two-center cohort study of patients with STEMI treated with primary percutaneous coronary intervention comprising stent implantation. All included patients underwent CMR imaging before discharge. Major adverse cardiac events (MACE) and LV remodeling were assessed during 6 months of follow-up.

Results: Seventy-six patients were available for the final analysis. The MACE rate was $23.7 \%$, using cardiac death, reinfarction, unplanned revascularization, and heart failure as combined events during 6 months of follow-up. The global longitudinal strain (GLS) was an independent predictor of MACE (OR=1.21 (1.071.36), $\mathrm{P}=0.002)$ and $L V$ remodeling $(\mathrm{OR}=2.06$ (1.14-3.73), $\mathrm{P}=0.017)$.

Conclusion: In patients with STEMI treated with primary percutaneous coronary intervention, the GLS determined on CMR imaging performed before discharge is a predictor of MACE and adverse LV remodeling during 6 months of follow-up.

\section{Background}

Patients with acute ST-segment elevation myocardial infarction (STEMI) have a high risk of adverse outcomes, even after timely revascularization $(1,2)$. Hence, early risk stratification of such patients is clinically important. Patients with STEMI treated with stent implantation often exhibit remodeling of the left ventricle. As left ventricular (LV) remodeling is associated with future adverse outcomes, changes in cardiac parameters may be risk factors for adverse events after revascularization in patients with STEMI.

Substantial studies have reported the superior prognostic power of global longitudinal strain (GLS) for predicting LV remodeling and predicting adverse events using the speckle tracking echocardiography technique (3-5). However, cardiac magnetic resonance (CMR) imaging is considered the gold standard for the assessment of regional myocardial strain. CMR feature tracking (CMR-FT) acquires steady-state freeprecession cine images and accurately predicts transmural infarction, myocardial deformation, and wall motion $(6,7)$. Although CMRFT indices show independent prognostic implications in dilated and chronic ischemic cardiomyopathy as well as tetralogy of Fallot (8-10), the usefulness of CMR-FT in myocardial infarction is controversial $(11,12)$. Eitel et al. suggested an incremental prognostic role of CMR-FT-derived GLS above classical CMR prognostic markers in patients with acute myocardial infarction (including STEMI and non-STEMI) (11). In contrast, a retrospective study failed to demonstrate a prognostic value of GLS over other established CMR parameters in 323 patients with STEMI (12).

The objective of the present study was to assess the effects of CMR-determined cardiac strain on cardiac events and adverse LV remodeling. We hypothesized that cardiac GLS measured before discharge is a good 
predictor of cardiac events and adverse LV remodeling after revascularization for STEMI. To test this hypothesis, the present prospective two-center study evaluated patients with STEMI treated with primary percutaneous coronary intervention $(\mathrm{PCl})$ comprising stent implantation. These patients underwent $\mathrm{CMR}$ imaging before discharge. Follow-up data at 6 months after treatment were obtained from hospital records or face-to-face visits. The study findings will aid in the prediction of adverse events after revascularization in patients with STEMI.

\section{Methods}

Study Design: This prospective cohort study was performed in Peking University First Hospital and the Affiliated Hospital of Xuzhou Medical University. The study was approved by the Institutional Review Board of each participating center, and conformed to the Declaration of Helsinki and Good Clinical Practice Guidelines of the China Food and Drug Administration. All patients provided written informed consent.

Participants: The study cohort comprised 86 patients with STEMI treated with primary PCl comprising stent implantation in one of the two participating centers from February 2015 to September 2016. All patients underwent CMR imaging before discharge.

Exclusion criteria were: 1) atrial fibrillation, frequent premature contractions, persistent ventricular tachycardia, or other tachyarrhythmia; 2) previous cardiac surgery or myocardial infarction; 3) severe liver and/or kidney dysfunction; 4) malignancy; 5) life expectancy of less than 1 year; 6) pregnancy; and 7) contraindications to magnetic resonance imaging (e.g. contrast agent allergy, ferromagnetic objects in the body, claustrophobia).

CMR Imaging Measurements: CMR imaging was performed before discharge (generally 5-7 days after the index event). All patients were examined with a 1.5 Tesla GE magnetic resonance imaging scanner. Three long-axis views (four-, three-, and two-chamber orientation) and short-axis stacks were acquired using a balanced steady-state free-precession imaging technique for functional cardiac analyses. Native T2, T2weighted, and post-contrast T1-weighted image sequences were used for the assessment of edema, infarction size, microvascular obstruction (MVO), and intramyocardial hemorrhage. T1-weighted images were obtained 15 minutes after the administration of gadolinium-based contrast agent.

CMR Imaging Analysis: The analysis was performed offline by two experienced radiologists. Infarct size, edema, MVO, and intramyocardial hemorrhage were quantified using CVI 42 software (Circle Cardiovascular Imaging Calgary, Canada) (13). CMR-FT strains (GLS, global circumferential strain (GCS), and global radial strain (GRS), LV end-diastolic volume (LVEDV), LV end-systolic volume, and LV ejection fraction (LVEF) were determined using the TomTec Imaging System (2D CPA MR, Cardiac Performance Analysis, version 1.1.2, TomTec Imaging Systems, Germany) $(14,15)$. Briefly, LV contours were drawn semi-automatically at the end of diastole and systole. Subsequently, image features throughout an entire cardiac cycle were determined by the automatic border tracking algorithm of the software. Accurate tracking was confirmed by visual review of all borders and manual adjustments with consequent reapplication of the algorithm if necessary. 
Follow-up Examination: The incidence of major adverse cardiac events (MACE), including cardiac death, reinfarction, unplanned revascularization, and heart failure within 6 months after STEMI was obtained from hospital records or face-to-face visits. Heart failure manifestations were defined as the exacerbation of exertional dyspnea or pulmonary edema requiring hospital admission, initiation of diuretics, or an increase in an existing diuretic regimen. Follow-up CMR imaging was performed at 6 months after STEMI. Adverse LV remodeling was defined as an LVEDV of $>15 \%$ greater than the LVEDV before discharge from the hospital.

Statistical Analysis: Variables are denoted as mean \pm standard deviation, and the independent $t$ test or Fisher exact test was used to compare differences between groups. Variables that were not normally distributed (as determined by Kolmogorov-Smirnov tests) were expressed as medians with 25th and 75th percentiles, and were compared using the Mann-Whitney $\mathrm{U}$ test. Based on the ratio of the infarcted myocardial mass to the LV mass (IM\%LV), patients were divided into group A (IM\%LV < 10\%), group B (10\% $\leq \mathrm{IM} \% \mathrm{LV}<20 \%)$, and group C (IM\%LV $\geq 20 \%)$.

A comparison of multiple variables was performed between patients with $L V$ remodeling and patients without LV remodeling, and between patients who did and did not develop MACE during follow-up. Uni- and multivariate logistic backward stepwise regression analyses were performed to evaluate the potential correlations between clinical parameters and CMR imaging parameters to MACE and LV remodeling. Because of the small sample size, the parameters with a $p$ value $<0.05$ in comparisons between the MACE and no MACE groups (and between the LV remodeling and no LV remodeling groups), sex, and age were selected for the logistic regression analysis. If there were multiple parameters with high correlations, only the most clinically significant parameter was selected for the analysis. For example, as LVEDV, LV endsystolic volume, and LVEF were highly correlated, only LVEF was used in the analysis. Receiver operatingcharacteristic (ROC) curve analysis was used to determine the cutoff values of the GLS for predicting MACE. All statistical analyses were performed with a test significance level of 0.05 using SAS version 9.4 (SAS Institute, Inc., Cary, NC).

\section{Results}

The follow-up analysis was carried out in 76 patients (age $55.5 \pm 10.7$ years; $88 \%$ male) who were treated with primary PCl for STEMI and underwent CMR imaging examination before discharge, as shown in Fig. 1. Baseline patient characteristics are presented in Table 1. The most commonly accessed vessel was the left anterior descending artery, followed by the right coronary artery and left circumflex artery. The baseline characteristics that differed between patients with different degrees of myocardial infarction were the peak brain natriuretic peptide (BNP) level, peak cardiac troponin I level, and symptom-to-balloon time.

Table 2 lists the cardiac characteristics obtained from CMR imaging at baseline. Group C had the lowest absolute GLS, GCS, and GRS values and the lowest LVEF, while group A had the highest values. Group C also had the worst features regarding the other variables. In 6 months of follow-up, MACE occurred in 18 patients $(23.7 \%)$, including one patient with cardiac death, one with non-fatal reinfarction, four with unplanned revascularization, and 12 with heart failure. Patients with a higher IM\%LV had a higher incidence 
of MACE than those with a lower IM\%LV. Table 3 summarizes the baseline clinical and CMR imaging characteristics of the patients with MACE compared with those without MACE. Patients with MACE had a higher peak BNP level, higher peak cardiac troponin I level, longer hospital stay, longer symptom-to-balloon time, and worse CMR parameters than those with no MACE.

Univariate logistic regression analysis revealed that the variables predicting MACE were peak BNP level, LVEF, IM\%LV, MVO, GLS, and GCS. Backward stepwise multivariate analysis confirmed that GLS was an independent predictor of MACE ( $O R=1.21$ (1.07-1.36); $P=0.001$; Table 4). Figure 2 shows the ROC curve of the GLS. The area under the ROC curve was 0.763 . The best cutoff value of GLS for predicting MACE was $-14.6 \%$, with a diagnostic sensitivity of $72.2 \%$ and a diagnostic specificity of $74.2 \%$.

CMR imaging was performed at 6 months after STEMI in 24 patients (age $54 \pm 11$ years; $88 \%$ male). CMR imaging parameters showed improved cardiac function at 6 months after STEMI treatment compared with baseline (Table 5). Table 6 shows a comparison of the clinical and CMR imaging characteristics at baseline in patients with LV remodeling versus patients without LV remodeling on follow-up examination. Univariate logistic regression analysis revealed that the variables predicting LV remodeling were symptom-to-balloon time and GLS. Backward stepwise multivariate analysis confirmed that GLS was an independent predictor of $L V$ remodeling ( $O R=2.06$ (1.14-3.73); $P=0.017$; Table 7).

\section{Discussion}

The present study showed the usefulness of GLS in the prediction of MACE and LV remodeling after PCI in patients with STEMI. After adjustments for clinical and morphometric parameters, the CMR-determined GLS before discharge was independently associated with adverse remodeling and outcomes at 6 months after STEMI treatment.

\section{Relationship between GLS and MACE}

The present study reported a MACE rate of $23.7 \%$, using cardiac death, reinfarction, unplanned revascularization, and heart failure as combined events. Previous studies have reported similar MACE rates of $22 \%$ using cardiac death and heart failure as combined events (16), and $21 \%$ using cardiac death, acute myocardial infarction, and heart failure as combined events (17).

When measured soon after revascularization, the LVEF is a proven predictor of poor outcome in patients with myocardial infarction (18-20). However, the LVEF is a global parameter that represents the entire LV function and is thus a weak predictor of late myocardial dysfunction $(21,22)$. Assessments of the myocardial strain in the circumferential, longitudinal, and radial directions (i.e., GLS, GCS, and GRS, respectively) are sensitive markers of intrinsic myocardial function, providing an improved analysis of cardiac dysfunction early after myocardial infarction on local and global levels $(7,23)$. Myocardial strain assessed using the speckle tracking echocardiography technique accurately predicts adverse events (2426). Based on the gold standard CMR imaging measurements (27-29), the present study showed that GLS was an independent predictor of MACE, with an optimal cutoff value of $-14.6 \%$. Similarly, previous studies have reported that GLS is a strong and independent predictor of adverse events $(30,31)$, and a study of 659 
patients with acute myocardial infarction demonstrated that a GLS value of greater than $-15.1 \%$ was an independent predictor of cardiovascular events, either by combining all events or separating these events into mortality, reinfarction, revascularization, and hospitalization for heart failure (30).

\section{Relationship between GLS and LV remodeling}

Even after $\mathrm{PCl}$, adverse LV remodeling occurs in $30-35 \%$ of patients with STEMI (32), and is an important predictor of arrhythmias, heart failure, and mortality $(33,34)$. In the present study, the rate of adverse LV remodeling at 6 months after STEMI treatment was $29 \%$, which is similar to the rate reported in a previous study (35). Although the LVEF is routinely used to assess LV systolic function, it cannot predict the development of LV remodeling. GLS is reportedly an independent predictor of adverse LV remodeling $(16,30,35)$. The present study confirmed that GLS was an independent predictor of adverse LV remodeling. Similarly, a previous prospective study identified GLS as a strong predictor of clinical outcomes and an independent predictor of MACE and LV remodeling in multivariable logistic regression analysis after adjustment for other established prognostic risk factors, including the LVEF and infarct size $(11,12)$.

\section{Study Limitations}

The present study has several limitations. First, the sample size was relatively small and was limited to patients with STEMI treated with primary PCl comprising stent implantation in two centers. Hence, selection bias and low statistical power should be considered when interpreting the findings. Second, patients with cardiogenic shock and those requiring mechanical ventilation or intra-aortic balloon counter-pulsation therapy were not included. Third, the echocardiographic GLS was not measured, and so could not be compared with the CMR-derived GLS. Finally, heart rate and blood pressure, which influence strain computation, were not available for all patients when underwent CMR imaging.

\section{Conclusions}

In patients with STEMI treated with primary $\mathrm{PCl}$, the CMR-determined GLS before discharge was a predictor of MACE and adverse LV remodeling at 6 months after STEMI treatment. Hence, GLS has potential as a risk factor to quantify ventricular dysfunction.

\section{Declarations}

Ethics approval and consent to participate: The study was approved by the Institutional Review Board of each participating center, and conformed to the Declaration of Helsinki and Good Clinical Practice Guidelines of the China Food and Drug Administration. All patients provided written informed consent for study participation.

Consent for publication: Not applicable.

Availability of data and materials: The datasets used and/or analyzed in the current study are available from the corresponding author on reasonable request. 
Competing interests: The authors declare that they have no competing interests.

Funding: None.

Authors' contributions: Yanjun Gong and Yuan Lu assessed the patients for study eligibility, performed data analysis, and wrote and edited the manuscript. Jessica C. Huo polished the language of the manuscript. Zhi Wang, Fan Yang, and Lin Qiu helped perform the patient follow-up and data collection. Shu Fang edited the manuscript. Jianxing Qiu performed cardiac magnetic resonance imaging. Yong Huo helped in designing the study, performing data analysis, and editing the manuscript.

Acknowledgements: We thank Kelly Zammit, BVSc, from Liwen Bianji, Edanz Editing China (www.liwenbianji.cn/ac), for editing the English text of a draft of this manuscript.

\section{Abbreviations}

STEMI: ST-segment elevation myocardial infarction; LV: Left ventricular; MVO : Microvascular obstruction; GLS: Global longitudinal strain; CMR:Cardiac magnetic resonance; CMR-FT : CMR feature tracking; PCl: Percutaneous coronary intervention; GCS: Global circumferential strain; GRS: Global radial strain; LVEDV: LV end-diastolic volume; LVEF: LV ejection fraction; MACE: Major adverse cardiac events; IM\%LV: The infarcted myocardial mass to the LV mass ROC: Receiver operating-characteristic; BNP: brain natriuretic peptide.

\section{References}

1. Palmerini T, Biondi-Zoccai G, Della Riva D et al. Clinical outcomes with drug-eluting and bare-metal stents in patients with ST-segment elevation myocardial infarction: evidence from a comprehensive network meta-analysis. Journal of the American College of Cardiology 2013;62:496-504.

2. Moon J, Kang W, Oh PC et al. Serum transaminase determined in the emergency room predicts outcomes in patients with acute ST-segment elevation myocardial infarction who undergo primary percutaneous coronary intervention. International journal of cardiology 2014;177:442-7.

3. Russo C, Jin Z, Elkind MS et al. Prevalence and prognostic value of subclinical left ventricular systolic dysfunction by global longitudinal strain in a community-based cohort. European journal of heart failure 2014;16:1301-9.

4. Motoki $\mathrm{H}$, Borowski $\mathrm{AG}$, Shrestha $\mathrm{K}$ et al. Incremental prognostic value of assessing left ventricular myocardial mechanics in patients with chronic systolic heart failure. Journal of the American College of Cardiology 2012;60:2074-81.

5. Levy PT, Machefsky A, Sanchez AA et al. Reference Ranges of Left Ventricular Strain Measures by TwoDimensional Speckle-Tracking Echocardiography in Children: A Systematic Review and Meta-Analysis. Journal of the American Society of Echocardiography : official publication of the American Society of Echocardiography 2016;29:209-225.e6.

6. Khan JN, Singh A, Nazir SA, Kanagala P, Gershlick AH, McCann GP. Comparison of cardiovascular magnetic resonance feature tracking and tagging for the assessment of left ventricular systolic strain 
in acute myocardial infarction. European journal of radiology 2015;84:840-8.

7. Schuster A, Hor KN, Kowallick JT, Beerbaum P, Kutty S. Cardiovascular Magnetic Resonance Myocardial Feature Tracking: Concepts and Clinical Applications. Circ Cardiovasc Imaging 2016;9:e004077.

8. Buss SJ, Breuninger K, Lehrke S et al. Assessment of myocardial deformation with cardiac magnetic resonance strain imaging improves risk stratification in patients with dilated cardiomyopathy. European heart journal cardiovascular Imaging 2015;16:307-15.

9. Romano S, Judd RM, Kim RJ et al. Feature-Tracking Global Longitudinal Strain Predicts Death in a Multicenter Population of Patients With Ischemic and Nonischemic Dilated Cardiomyopathy Incremental to Ejection Fraction and Late Gadolinium Enhancement. JACC Cardiovascular imaging 2018;11:1419-1429.

10. Orwat S, Diller GP, Kempny A et al. Myocardial deformation parameters predict outcome in patients with repaired tetralogy of Fallot. Heart (British Cardiac Society) 2016;102:209-15.

11. Eitel I, Stiermaier T, Lange T et al. Cardiac Magnetic Resonance Myocardial Feature Tracking for Optimized Prediction of Cardiovascular Events Following Myocardial Infarction. JACC Cardiovascular imaging 2018;11:1433-1444.

12. Gavara J, Rodriguez-Palomares JF, Valente F et al. Prognostic Value of Strain by Tissue Tracking Cardiac Magnetic Resonance After ST-Segment Elevation Myocardial Infarction. JACC Cardiovascular imaging 2018;11:1448-1457.

13. Niu P, Li L, Yin Z, Du J, Tan W, Huo Y. Speckle tracking echocardiography could detect the difference of pressure overload-induced myocardial remodelling between young and adult rats. J R Soc Interface 2020;17:20190808.

14. Schuster A, Kutty S, Padiyath A et al. Cardiovascular magnetic resonance myocardial feature tracking detects quantitative wall motion during dobutamine stress. Journal of cardiovascular magnetic resonance : official journal of the Society for Cardiovascular Magnetic Resonance 2011;13:58.

15. Schuster A, Paul M, Bettencourt N et al. Myocardial feature tracking reduces observer-dependence in low-dose dobutamine stress cardiovascular magnetic resonance. PloS one 2015;10:e0122858.

16. Park YH, Kang SJ, Song JK et al. Prognostic value of longitudinal strain after primary reperfusion therapy in patients with anterior-wall acute myocardial infarction. Journal of the American Society of Echocardiography : official publication of the American Society of Echocardiography 2008;21:262-7.

17. Lacalzada J, de la Rosa A, Izquierdo MM et al. Left ventricular global longitudinal systolic strain predicts adverse remodeling and subsequent cardiac events in patients with acute myocardial infarction treated with primary percutaneous coronary intervention. The international journal of cardiovascular imaging 2015;31:575-84.

18. Rouleau JL, Talajic M, Sussex B et al. Myocardial infarction patients in the 1990s-their risk factors, stratification and survival in Canada: the Canadian Assessment of Myocardial Infarction (CAMI) Study. Journal of the American College of Cardiology 1996;27:1119-27.

19. Eitel I, de Waha S, Wohrle J et al. Comprehensive prognosis assessment by CMR imaging after STsegment elevation myocardial infarction. Journal of the American College of Cardiology 2014;64:1217- 
26.

20. White HD, Norris RM, Brown MA, Brandt PW, Whitlock RM, Wild CJ. Left ventricular end-systolic volume as the major determinant of survival after recovery from myocardial infarction. Circulation 1987;76:4451.

21. Eitel I, Poss J, Jobs A et al. Left ventricular global function index assessed by cardiovascular magnetic resonance for the prediction of cardiovascular events in ST-elevation myocardial infarction. Journal of cardiovascular magnetic resonance : official journal of the Society for Cardiovascular Magnetic Resonance 2015;17:62.

22. Dagres N, Hindricks G. Risk stratification after myocardial infarction: is left ventricular ejection fraction enough to prevent sudden cardiac death? European heart journal 2013;34:1964-71.

23. Shetye A, Nazir SA, Squire IB, McCann GP. Global myocardial strain assessment by different imaging modalities to predict outcomes after ST-elevation myocardial infarction: A systematic review. World journal of cardiology 2015;7:948-60.

24. Gotte MJ, van Rossum AC, Twisk JWR, Kuijer JPA, Marcus JT, Visser CA. Quantification of regional contractile function after infarction: strain analysis superior to wall thickening analysis in discriminating infarct from remote myocardium. Journal of the American College of Cardiology 2001;37:808-17.

25. Biering-Sorensen T, Jensen JS, Pedersen SH et al. Regional Longitudinal Myocardial Deformation Provides Incremental Prognostic Information in Patients with ST-Segment Elevation Myocardial Infarction. PloS one 2016;11:e0158280.

26. Joyce E, Hoogslag GE, Leong DP et al. Association between left ventricular global longitudinal strain and adverse left ventricular dilatation after ST-segment-elevation myocardial infarction. Circulation Cardiovascular imaging 2014;7:74-81.

27. Reinstadler SJ, Thiele H, Eitel I. Risk stratification by cardiac magnetic resonance imaging after STelevation myocardial infarction. Current opinion in cardiology 2015;30:681-9.

28. Schuster A, Morton G, Chiribiri A, Perera D, Vanoverschelde JL, Nagel E. Imaging in the management of ischemic cardiomyopathy: special focus on magnetic resonance. Journal of the American College of Cardiology 2012;59:359-70.

29. Ferrari VA, Duffy KJ. Cardiovascular Magnetic Resonance Imaging. Totowa, New Jersey: Humana Press, 2008.

30. Antoni ML, Mollema SA, Delgado V et al. Prognostic importance of strain and strain rate after acute myocardial infarction. European heart journal 2010;31:1640-7.

31. Stanton T, Leano R, Marwick TH. Prediction of all-cause mortality from global longitudinal speckle strain: comparison with ejection fraction and wall motion scoring. Circulation Cardiovascular imaging 2009;2:356-64.

32. Bolognese L, Neskovic AN, Parodi G et al. Left ventricular remodeling after primary coronary angioplasty: patterns of left ventricular dilation and long-term prognostic implications. Circulation 2002;106:2351-7. 
33. St John Sutton M, Lee D, Rouleau JL et al. Left ventricular remodeling and ventricular arrhythmias after myocardial infarction. Circulation 2003;107:2577-82.

34. Pfeffer MA, Braunwald E. Ventricular remodeling after myocardial infarction. Experimental observations and clinical implications. Circulation 1990;81:1161-72.

35. Bochenek T, Wita K, Tabor Z et al. Value of speckle-tracking echocardiography for prediction of left ventricular remodeling in patients with ST-elevation myocardial infarction treated by primary percutaneous intervention. Journal of the American Society of Echocardiography : official publication of the American Society of Echocardiography 2011;24:1342-8.

\section{Tables}

Table 1. Baseline characteristics of the study population 


\begin{tabular}{|c|c|c|c|c|c|}
\hline Variables & $\begin{array}{l}\text { Total } \\
(\mathrm{n}=76)\end{array}$ & $\begin{array}{l}\text { Group A } \\
(\mathrm{n}=29) \\
(\mathrm{IM} \% \mathrm{LV}<10 \%)\end{array}$ & $\begin{array}{l}\text { Group B }(n=33) \\
(10 \% \leq \mathrm{IM} \% \mathrm{LV}<20 \%)\end{array}$ & $\begin{array}{l}\text { Group C } \\
(\mathrm{n}=14) \\
(\mathrm{IM} \% \mathrm{LV} \geq 20 \%)\end{array}$ & $\mathrm{P}$ \\
\hline Age (years) & $55.5 \pm 10.7$ & $53.7 \pm 11.3$ & $56.7 \pm 9.6$ & $56.3 \pm 12.1$ & 0.519 \\
\hline Male (n, \%) & $67(88.2)$ & $26(89.7)$ & 29 (87.9) & $12(85.7)$ & 0.930 \\
\hline BMI $\left(\mathrm{kg} / \mathrm{m}^{2}\right)$ & $24.9 \pm 3.1$ & $25.0 \pm 3.3$ & $24.4 \pm 3.0$ & $25.7 \pm 2.7$ & 0.422 \\
\hline $\begin{array}{l}\text { Smoking (n, } \\
\%)\end{array}$ & $50(65.8)$ & $17(58.6)$ & $25(75.7)$ & $8(57.1)$ & 0.275 \\
\hline $\begin{array}{l}\text { Diabetes } \\
\text { mellitus (n, } \\
\%)\end{array}$ & $12(15.8)$ & $3(10.3)$ & $6(18.2)$ & $3(21.4)$ & 0.570 \\
\hline $\begin{array}{l}\text { Hypertension } \\
(\mathrm{n}, \%)\end{array}$ & $38(50)$ & $16(55.2)$ & $17(51.5)$ & $5(35.7)$ & 0.476 \\
\hline $\begin{array}{l}\text { Systolic } \\
\text { blood } \\
\text { pressure } \\
\text { (mmHg) }\end{array}$ & $135 \pm 9$ & $140 \pm 19$ & $130 \pm 18$ & $136 \pm 16$ & 0.164 \\
\hline $\begin{array}{l}\text { Heart rate } \\
\text { (beats/min) }\end{array}$ & $73.5 \pm 10.5$ & $75.4 \pm 10.2$ & $73.1 \pm 11.1$ & $74.4 \pm 9.4$ & 0.670 \\
\hline $\begin{array}{l}\text { LDL-C } \\
(\mathrm{mmol} / \mathrm{L})\end{array}$ & $2.8 \pm 0.8$ & $2.8 \pm 0.7$ & $2.7 \pm 0.7$ & $2.8 \pm 1.2$ & 0.787 \\
\hline $\begin{array}{l}\text { HDL-C } \\
(\mathrm{mmol} / \mathrm{L})\end{array}$ & $1.1 \pm 0.2$ & $1.1 \pm 0.2$ & $1.0 \pm 0.2$ & $1.1 \pm 0.4$ & 0.123 \\
\hline $\begin{array}{l}\text { Peak BNP } \\
(\mathrm{pg} / \mathrm{ml})\end{array}$ & $1452 \pm 1219$ & $626 \pm 698$ & $1500 \pm 1019$ & $3051 \pm 1648$ & $<0.001$ \\
\hline $\begin{array}{l}\text { Peak cTNI } \\
(\mathrm{ng} / \mathrm{ml})\end{array}$ & $\begin{array}{l}8.53(3.39, \\
14.29)\end{array}$ & $2.6(1.4,4.25)$ & $11.4(8.02,14.9)$ & $\begin{array}{l}26.4(13.1, \\
69.8)\end{array}$ & $<0.001$ \\
\hline $\begin{array}{l}\text { Multivessel } \\
\text { coronary } \\
\text { disease (n, } \\
\%)\end{array}$ & $21(27.6)$ & $6(20.7)$ & $10(30.3)$ & $5(35.7)$ & 0.529 \\
\hline $\begin{array}{l}\text { Culprit } \\
\text { lesion on } \\
\text { CAG LAD (n, } \\
\%)\end{array}$ & $43(56.6)$ & $16(55.2)$ & $18(54.5)$ & $9(64.3)$ & 0.812 \\
\hline $\begin{array}{l}\text { Hospital } \\
\text { stay (days) }\end{array}$ & $10(8,12)$ & $8(7,10)$ & $10(8,12)$ & $11(10,13)$ & 0.091 \\
\hline $\begin{array}{l}\text { TIMI flow } \\
\text { frame count } \\
\text { (frames) }\end{array}$ & $28(20,37)$ & $28(21.2,38.9)$ & $26(18.82,36.0)$ & $\begin{array}{l}33.0(25.9, \\
38.0)\end{array}$ & 0.476 \\
\hline $\begin{array}{l}\text { TIMI } \\
\text { Myocardial } \\
\text { Perfusion } \\
\text { Classification } \\
\leq \text { level } 2 \text { (n, } \\
\% \text { ) }\end{array}$ & $4(5.26)$ & $2(6.8)$ & $1(3.03)$ & $1(7.1)$ & 0.362 \\
\hline $\begin{array}{l}\text { Symptom to } \\
\text { balloon time } \\
\text { (minutes) }\end{array}$ & $346 \pm 156$ & $219 \pm 115$ & $369 \pm 110$ & $535 \pm 130$ & 0.002 \\
\hline $\begin{array}{l}\text { With } \\
\text { Collateral } \\
\text { circulation } \\
(\mathrm{n}, \%)\end{array}$ & $11(14.5)$ & $6(20.9)$ & $4(12.1)$ & $1(7.1)$ & 0.436 \\
\hline
\end{tabular}


IM\%LV: infarcted myocardial mass/left ventricular mass; LDL-C: low-density lipoprotein cholesterol; HDL-C: high-density lipoprotein cholesterol; BNP: brain natriuretic peptide; cTNI: cardiac troponin I.

Table 2. Cardiac characteristics obtained from CMR imaging at baseline

\begin{tabular}{lllll}
\hline Variables & $\begin{array}{l}\text { Group A }(\mathrm{n}=29) \\
(\mathrm{IM} \% \mathrm{LV}<10 \%)\end{array}$ & $\begin{array}{l}\text { Group B }(\mathrm{n}=33) \\
(10 \% \leq \mathrm{IM} \% \mathrm{LV}<20 \%)\end{array}$ & $\begin{array}{l}\text { Group C }(\mathrm{n}=14) \\
(\mathrm{IM} \% \mathrm{LV} \geq 20 \%)\end{array}$ & $\mathrm{P}$ \\
\hline LVEDV (ml) & $123.9 \pm 14.8$ & $124.2 \pm 12.3$ & $144.6 \pm 16.2$ & 0.037 \\
LVESV (ml) & $57.1 \pm 16.1$ & $66.14 \pm 11.6$ & $80.5 \pm 12.5$ & 0.021 \\
LVEF (\%) & $57.5 \pm 7.5$ & $47.7 \pm 7.6$ & $44.2 \pm 4.6$ & $<0.001$ \\
IMH & $2(6.9 \%)$ & $7(21.2 \%)$ & $6(42.9 \%)$ & 0.020 \\
MVO & $7(24.1 \%)$ & $18(54.5 \%)$ & $11(78.5 \%)$ & 0.002 \\
IMH+MVO & $2(6.9 \%)$ & $7(21.2 \%)$ & $6(42.9 \%)$ & 0.020 \\
Edema/LV (\%) & $23.3(20.5,30.2)$ & $32.3(27.5,38.0)$ & $36.12(34.2,39.1)$ & 0.002 \\
Salvage/LV (\%) & $18.8(14.9,24.6)$ & $17.8(12.9,21.9)$ & $12.1(6.0,14.4)$ & 0.002 \\
IM\%LV (\%) & $6.2 \pm 5.2$ & $14.5 \pm 5.8$ & $26.0 \pm 7.3$ & 0.002 \\
GLS (\%) & $-18.8 \pm 3.8$ & $-15.6 \pm 3.5$ & $-7.3 \pm 2.2$ & $\mathrm{P}<0.001$ \\
GCS (\%) & $-28.2 \pm 5.16$ & $-22.5 \pm 5.6$ & $-18.4 \pm 3.25$ & $\mathrm{P}<0.001$ \\
GRS (\%) & $36.87(33.5,42.4)$ & $30.24(23.6,37.5)$ & $24.58(20.6,32.6)$ & $\mathrm{P}=0.005$ \\
\hline
\end{tabular}

LVEDV: left ventricular end-diastolic volume; LVESV: left ventricular end-systolic volume; LVEF: left ventricular ejection fraction; IMH: intramyocardial hemorrhage; MVO: microvascular obstruction; GLS: global longitudinal strain; GCS: global circumferential strain; GRS: global radial strain.

Table 3. Baseline clinical and CMR imaging characteristics by presence or absence of MACE 


\begin{tabular}{|c|c|c|c|}
\hline Variables & $\begin{array}{l}\text { MACE } \\
(n=18)\end{array}$ & $\begin{array}{l}\text { no MACE } \\
(\mathrm{n}=58)\end{array}$ & $\mathrm{P}$ \\
\hline Age (years) & $55.6 \pm 8.7$ & $55.2 \pm 11.3$ & 0.627 \\
\hline Male (n, \%) & $17 \square 94.4 \square$ & $50 \square 86.2 \square$ & 0.598 \\
\hline BMI $\left(\mathrm{kg} / \mathrm{m}^{2}\right)$ & $25.6 \pm 2.9$ & $24.66 \pm 3.09$ & 0.244 \\
\hline Smoking $(\mathrm{n}, \%)$ & $11 \square 61.1 \square$ & $39 \square 67.2 \square$ & 0.229 \\
\hline Diabetes mellitus ( $\mathrm{n}, \%)$ & $3 \square 16.7 \square$ & $9 \square 15.5 \square$ & 0.999 \\
\hline Hypertension (n, \%) & $11 \square 61.1 \square$ & $27 \square 46.6 \square$ & 0.281 \\
\hline Systolic blood pressure (mmHg) & $140 \pm 24$ & $134 \pm 17$ & 0.254 \\
\hline Heart rate (beats/min) & $77.5 \pm 10.3$ & $73.2 \pm 10.3$ & 0.125 \\
\hline LDL-C (mmol/L) & $2.91 \pm 0.75$ & $2.69 \pm 0.83$ & 0.331 \\
\hline HDL-C (mmol/L) & $1.03 \pm 0.26$ & $1.06 \pm 0.24$ & 0.561 \\
\hline Peak BNP (pg/ml) & $2309.5 \pm 1610.9$ & $1185.7 \pm 1157.6$ & 0.002 \\
\hline Peak cTNI (ng/ml) & $\begin{array}{l}12.7(4.81 \\
24.51)\end{array}$ & $\begin{array}{l}7.45 \\
(2.82,13.35)\end{array}$ & $<0.001$ \\
\hline Multivessel coronary disease $(n, \%)$ & $5 \square 27.8 \square$ & $16 \square 27.6 \square$ & 0.987 \\
\hline Culprit lesion on CAG LAD (n, \%) & $12 \llbracket 66.7 \square$ & $31 \square 53.4 \square$ & 0.323 \\
\hline Hospital stay time (days) & $12 \pm 4$ & $9 \pm 3$ & 0.011 \\
\hline TIMI flow frame count (frames) & $34 \llbracket 24-46 \square$ & $27 \square 20-36 \square$ & 0.113 \\
\hline $\begin{array}{l}\text { TIMI Myocardial Perfusion } \\
\text { Classification } \leq \text { level } 2 \text { (n, \%) }\end{array}$ & 3ロ16.7\ & $2 \square 3.4 \square$ & 0.152 \\
\hline $\begin{array}{l}\text { Symptom to balloon time } \\
\text { (minutes) }\end{array}$ & $442.7 \pm 255.7$ & $315.7 \pm 298.6$ & 0.022 \\
\hline With Collateral circulation (n, \%) & $2(11.1 \%)$ & $9(15.5 \%)$ & 0.936 \\
\hline LVEDV (ml) & $141.2 \pm 22.5$ & $128.7 \pm 26.4$ & 0.034 \\
\hline LVESV (ml) & $76.1 \pm 15.6$ & $61.9 \pm 18.2$ & 0.002 \\
\hline LVEF (\%) & $46.1 \pm 6.9$ & $52.3 \pm 9.0$ & 0.009 \\
\hline $\mathrm{IMH}$ & $\begin{array}{l}6 \square 33.3 \% \square \\
\text { Page } 13 / 20\end{array}$ & $9 \square 15.5 \% \square$ & 0.020 \\
\hline
\end{tabular}




$\begin{array}{llll}\text { MVO } & 13 \square 72.2 \% \square & 23 \llbracket 39.7 \% \square & 0.002 \\ & & & \\ \text { IMH+ MVO } & 6 \square 33.3 \% \square & 9 \square 15.5 \% \square & 0.020 \\ & 34.50 \pm 8.76 & 30.40 \pm 8.79 & 0.094 \\ \text { Edema/LV (\%) } & 16.52 \pm 11.41 & 18.36 \pm 8.61 & 0.532 \\ \text { Salvage/LV (\%) } & 18.0 \pm 9.9 & 12.0 \pm 6.6 & 0.027 \\ \text { IM\%LV (\%) } & & & \\ & -11.44 \pm 5.07 & -16.48 \pm 4.8 & <0.001 \\ \text { GLS (\%) } & -20.6 \pm 5.1 & -24.9 \pm 6.2 & 0.008 \\ \text { GCS (\%) } & 25.7(20.2- & 34.7(25.8- & 0.015 \\ \text { GRS (\%) } & 32.6) & 39.4) & \end{array}$

IM\%LV: infarcted myocardial mass/left ventricular mass; LDL-C: low-density lipoprotein cholesterol; HDL-C: high-density lipoprotein cholesterol; BNP: brain natriuretic peptide; cTNI: cardiac troponin I; LVEDV: left ventricular end-diastolic volume; LVESV: left ventricular end-systolic volume; LVEF: left ventricular ejection fraction; IMH: intramyocardial hemorrhage; MVO: microvascular obstruction; GLS: global longitudinal strain; GCS: global circumferential strain; GRS: global radial strain.

Table 4. Correlation of clinical and CMR variables with MACE according to the logistic regression model using uni- and multivariate analyses 


\begin{tabular}{ccc}
\hline Variables & Univariate Analysis & $\begin{array}{c}\text { Multivariate Stepwise } \\
\text { Analysis }\end{array}$ \\
\cline { 2 - 3 } & OR $(95 \%$ CI $)$ P value & OR (95\%CI) P value \\
\hline Age, per 1 year & $1.01(0.96,1.06) 0.6217$ & - \\
Male vs Female & $2.72(0.32,23.36)$ & - \\
Peak BNP, per 100 pg/ml & $1.04(1.00,1.08) 0.0450$ & - \\
Peak cTNI, per 100 ng/ml & $1.02(0.99,1.04) 0.1723$ & - \\
Symptom to balloon & $1.04(0.99,1.09) 0.1246$ & - \\
time, & & \\
per 30 minutes & $0.91(0.85,0.98) 0.0137$ & - \\
LVEF, per 1\% & $3.68(1.16,11.71)$ & \\
MVO, yes vs no & 0.0271 & \\
IM\%LV, per 1\% & $1.10(1.02,1.18) 0.0102$ & \\
GLS, per 1\% & $1.16(1.05,1.28) 0.0040$ & $1.21(1.07,1.36) 0.0016$ \\
\hline GCS, per 1\% & $1.14(1.03,1.27) 0.0122$ & - \\
GRS, per 1\% & $0.93(0.85,1.03) 0.1554$ & - \\
\hline
\end{tabular}

BNP: brain natriuretic peptide; cTNI: cardiac troponin I; LVEF: left ventricular ejection fraction; MVO: microvascular obstruction; IM\%LV: infarcted myocardial mass/left ventricular mass; GLS: global longitudinal strain; GCS: global circumferential strain; GRS: global radial strain.

Table 5. Cardiac characteristics at baseline and after 6 months of follow-up 


\begin{tabular}{llll}
\hline Variables & $\begin{array}{l}\text { baseline } \\
(\mathrm{n}=24)\end{array}$ & $\begin{array}{l}6 \text { months } \\
(\mathrm{n}=24)\end{array}$ & $\mathrm{P}$ \\
\hline LVEDV (ml) & $145.2 \pm 21.23$ & $152.6 \pm 26.07$ & $<0.001$ \\
LVESV (ml) & $77.22 \pm 16.59$ & $74.41 \pm 24.52$ & $<0.001$ \\
LVEF (\%) & $46.85 \pm 7.74$ & $52.03 \pm 9.90$ & 0.002 \\
IM\%LV (\%) & $17.2(10.6,26.7)$ & $12.6(6.4,21.7)$ & $<0.001$ \\
GLS (\%) & $-13.22 \pm 4.89$ & $-16.16 \pm 5.84$ & 0.002 \\
GCS (\%) & $-22.88 \pm 5.74$ & $-23.21 \pm 6.92$ & 0.007 \\
GRS (\%) & $29.91 \pm 9.69$ & $33.40 \pm 9.14$ & 0.071 \\
\hline
\end{tabular}

LVEDV: left ventricular end-diastolic volume; LVESV: left ventricular end-systolic volume; LVEF: left ventricular ejection fraction; IM\%LV: infarcted myocardial mass/left ventricular mass; GLS: global longitudinal strain; GCS: global circumferential strain; GRS: global radial strain.

Table 6. Baseline clinical and CMR imaging characteristics by presence or absence of LV remodeling 


\begin{tabular}{|c|c|c|c|}
\hline CMR parameters & $\begin{array}{l}\text { LV remodeling } \\
(\mathrm{n}=7)\end{array}$ & $\begin{array}{l}\text { no } L V \\
\text { remodeling } \\
(n=17)\end{array}$ & $\mathrm{P}$ \\
\hline Age (years) & $58 \pm 8$ & $52 \pm 9$ & 0.152 \\
\hline Male (n, \%) & $6(85.7)$ & $15 \square 88.2 \square$ & 0.999 \\
\hline BMI $\left(\mathrm{kg} / \mathrm{m}^{2}\right)$ & $24.4 \pm 1.9$ & $25.8 \pm 2.6$ & 0.124 \\
\hline Smoking (n, \%) & $4 \llbracket 57.1 \square$ & $11(64.7)$ & 0.999 \\
\hline Diabetes mellitus (n, \%) & $1(14.3)$ & $2(11.8)$ & 0.999 \\
\hline Hypertension (n, \%) & $4(57.1)$ & $11(64.7)$ & 0.999 \\
\hline Systolic blood pressure (mmHg) & $141.0 \pm 21$ & $135.0 \pm 24$ & 0.614 \\
\hline Heart rate (beats/min) & $74 \pm 8$ & $77 \pm 12$ & 0.738 \\
\hline LDL-C (mmol/L) & $2.90 \pm 0.9$ & $2.83 \pm 0.9$ & 0.844 \\
\hline HDL-C (mmol/L) & $1.2 \pm 0.1$ & $1.0 \pm 0.2$ & 0.113 \\
\hline Peak BNP (pg/ml) & $1862.0 \pm 1359.4$ & $772.5 \pm 530.4$ & 0.080 \\
\hline Peak cTNI (ng/ml) & $\begin{array}{l}1934(564.1 \\
3666.0)\end{array}$ & $\begin{array}{l}480(49.93 \\
2559.5)\end{array}$ & $<0.001$ \\
\hline Multivessel coronary disease (n, \%) & $6(85.7)$ & $7(41.2)$ & 0.124 \\
\hline Culprit lesion on CAG LAD (n, \%) & $6(85.7)$ & $7(41.2)$ & 0.124 \\
\hline Hospital stay time (days) & $10.0 \pm 2.2$ & $10.2 \pm 2.5$ & 0.833 \\
\hline TIMI flow frame count (frames) & $35.9 \pm 6.5$ & $30.6 \pm 12.5$ & 0.251 \\
\hline $\begin{array}{l}\text { TIMI Myocardial Perfusion Classification } \leq \text { level } 2 \\
(\mathrm{n}, \%)\end{array}$ & $2(28.5)$ & $0(0.0)$ & 0.076 \\
\hline Symptom to balloon time (minutes) & $412.9 \pm 156.1$ & $185.1 \pm 44.9$ & 0.029 \\
\hline With Collateral circulation (n, \%) & $0(0 \%)$ & $2(11.8 \%)$ & 0.892 \\
\hline LVEDV (ml) & $141.1 \pm 13.7$ & $146.8 \pm 23.8$ & 0.564 \\
\hline LVESV (ml) & $82.7 \pm 11.3$ & $75.0 \pm 18.1$ & 0.308 \\
\hline LVEF (\%) & $41.6 \pm 3.4$ & $49.0 \pm 8.0$ & 0.004 \\
\hline $\mathrm{IMH}$ & $0(0 \%)$ & $4(23.5 \%)$ & 0.283 \\
\hline
\end{tabular}


$\mathrm{IMH}+\mathrm{MVO}$

Edema/LV (\%)

Salvage/LV (\%)

$\operatorname{IM}(\% \mathrm{LV})(\%)$

GLS (\%)

GRS (\%)

GCS (\%)
$0(0 \%)$

$33.42 \pm 9.86$

$12.51 \pm 7.00$

$26.8(22.5,30.0)$

$-7.9 \pm 4.1$

$28.7 \pm 10.7$

$-19.6 \pm 3.2$
4 (23.5\%)

0.283

$33.87 \pm 8.90$

0.916

$20.13 \pm 10.84$

0.102

$11.9(9.7,20.2)$

0.004

$-15.4 \pm 3.26$

$<0.001$

$30.4 \pm 9.6$

0.707

$-24.2 \pm 6.1$

0.071

IM\%LV: infarcted myocardial mass/left ventricular mass; LDL-C: low-density lipoprotein cholesterol; HDL-C: high-density lipoprotein cholesterol; BNP: brain natriuretic peptide; CTNI: cardiac troponin I; LVEDV: left ventricular end-diastolic volume; LVESV: left ventricular end-systolic volume; LVEF: left ventricular ejection fraction; IMH: intramyocardial hemorrhage; MVO: microvascular obstruction; GLS: global longitudinal strain; GCS: global circumferential strain; GRS: global radial strain.

Table 7. Correlation of clinical and CMR variables with LV remodeling according to the logistic regression model using uni- and multivariate analyses

Variables Univariate Analysis Multivariate Stepwise Analysis OR (95\%CI) P value OR (95\%CI) P value

Age, per 1 year

Male vs Female

Peak cTNI, per 100 ng/ml

Symptom to balloon time, per 30 minutes

LVEF, per $1 \%$

IM\%LV, per $1 \%$

GLS, per $1 \%$
$1.08(0.97,1.19) 0.1566$

$0.16(0.01,2.11) 0.1620$

$1.02(0.97,1.07) 0.4175$

$1.09(1.00,1.20) 0.0630$

$1.18(1.02,1.37) 0.0220$

$0.92(0.81,1.04) 0.1983$

$1.09(0.98,1.21) 0.1159$

$1.65(1.11,2.45) 0.0127$ $2.06(1.14,3.73) 0.0171$ 
IM\%LV: infarcted myocardial mass/left ventricular mass; cTNI: cardiac troponin I; LVEF: left ventricular ejection fraction; GLS: global longitudinal strain.

\section{Figures}

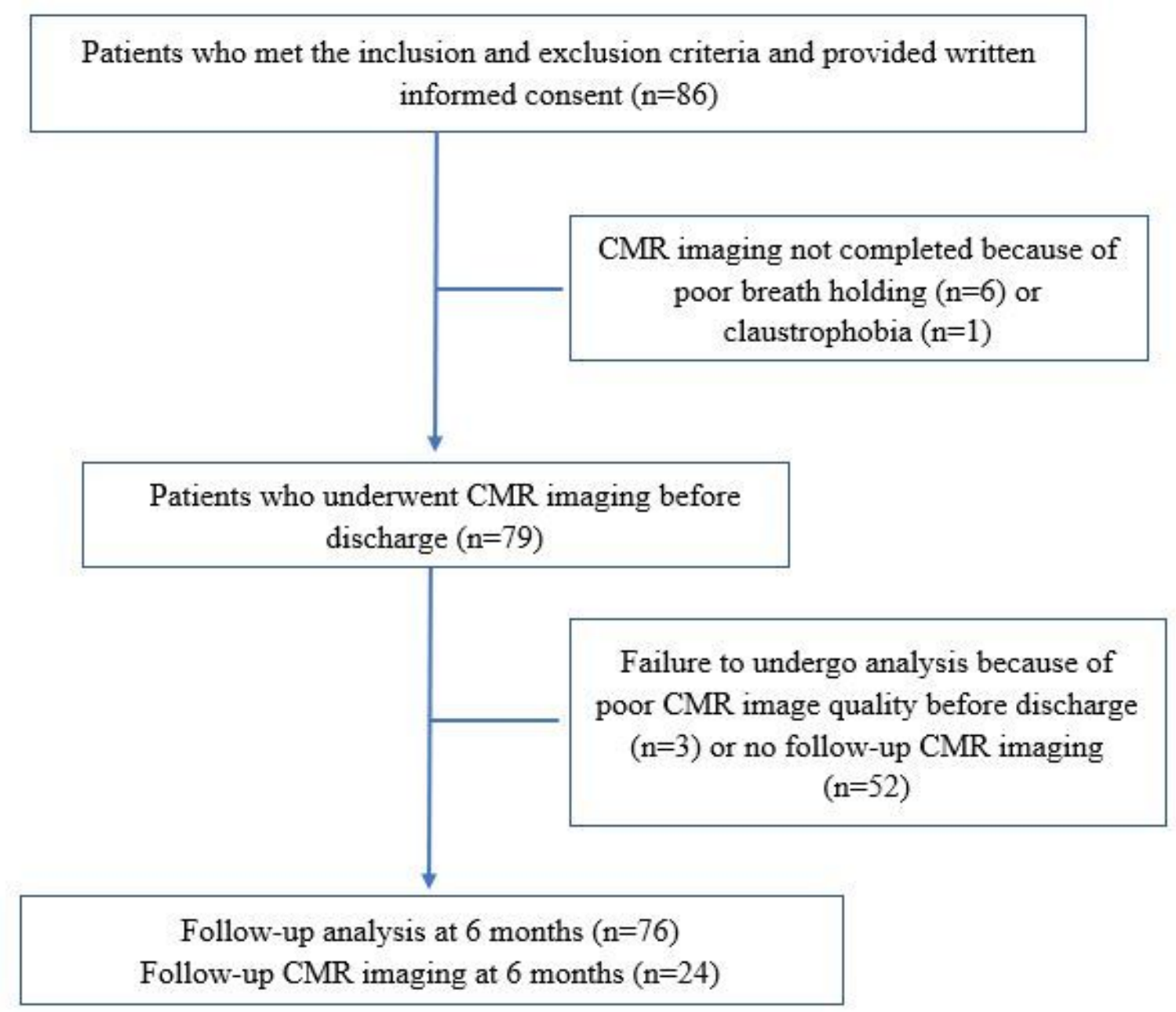

Figure 1

Flowchart of the study. CMR: cardiac magnetic resonance 


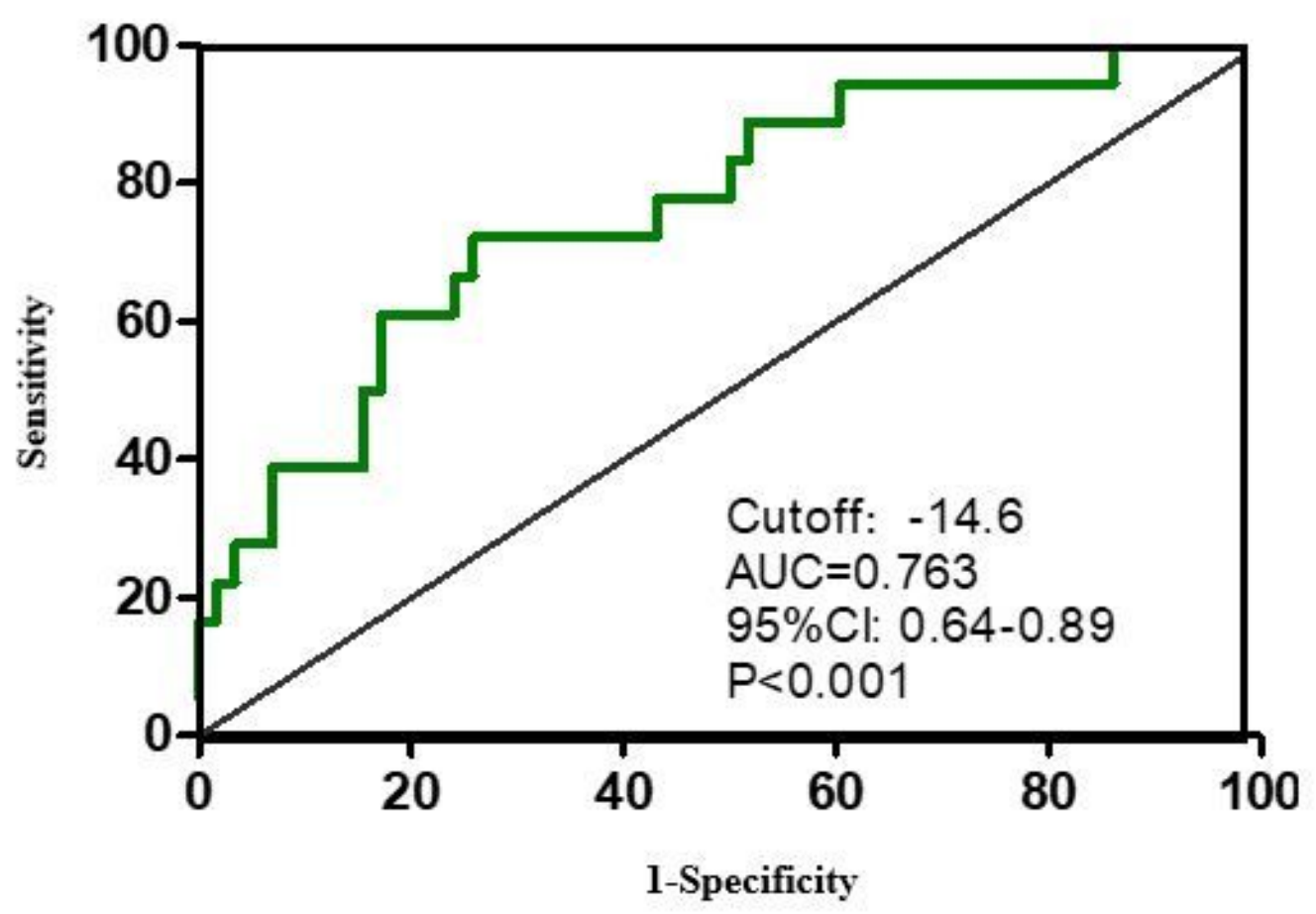

Figure 2

Receiver operating-characteristic curve for the prediction of major adverse cardiac events within 6 months after acute ST-segment elevation myocardial infarction, using the global longitudinal strain as the independent variable. 